\title{
EDITORIAL
}

\section{Perioperative Control of Serum Sodium for Liver Transplantation: Time for a More Aggressive Approach?}

\author{
Ala Nozari ${ }^{1, *}$ and Reza F. Saidi ${ }^{2}$
}

${ }^{I}$ Department of Anesthesia, Critical Care and Pain Medicine, Massachusetts General Hospital, Harvard Medical School, Boston, MA 02114, USA; ${ }^{2}$ Division of Organ Transplantation, Department of Surgery, University of Massachusetts Medical School, Worcester, MA 01655, USA

Keywords: Liver transplantation, hyponatremia, central pontine myelinolysis, furosemide, serum sodium, hepatic encephalopathy.

In this issue, Dr. D'Oyley reports a rather provocative approach to the perioperative management of hyponatremia, using data from two patients who underwent orthotopic liver transplantation. The author suggests that the routine administration of intravenous furosemide to induce a supranormal diuresis provides a better intraoperative control of serum sodium levels, which can potentially improve the long-term outcome.

Hyponatremia is common in patients with chronic liver disease because of low sodium diets, impaired renal handling of free water, and elevated levels of antidiuretic hormone. It may be exacerbated by aggressive diuretic use and is commonly treated with discontinuation of diuretics combined with free water restriction. Despite the evidence that a major tubular effect of furosemide is to inhibit sodium reabsorption in loops of Henle, it has been shown that the administration of the diuretic may result in a net increase in free water excretion in selected patients [1]. The suggested mechanism for an improved water excretion is through an incomplete osmotic equilibration that is achieved during high rates of flow through collecting ducts. Moreover, furosemide may interfere with proximal tubular reabsorption, resulting in an increased delivery of tubular fluid to diluting sites that are unaffected by the drug, and a net increase in the volume of dilute tubular fluid. Therefore, the proposed approach to administer furosemide during liver transplantation may in selected patients result in better perioperative control of hyponatremia. However, cirrhotic patients who require liver transplantation are severely compromised, and have variable degree of renal impairment, [2] making the response to furesmide very unpredictable. Consequently, routine use of furosemide is currently not advised in these patients because it can lead to a worsening of the hyponatremia or too rapid a correction of

*Address correspondence to this author at the Department of Anesthesiology, Critical Care, and Pain Medicine Massachusetts General, Hospital Harvard Medical School, 55, Fruit Street, Boston, MA 02114, USA;

Tel: +1-617-726-3030; Fax: +1- 617-643-2940;

E-mail: anozari@partners.org the electrolyte abnormality, with the risk for neurological complications.

Severe hyponatremia is generally considered a contraindication for surgery because of the risk of hepatic encephalopathy and central pontine myelinolysis (CPM). Indeed, it has been shown that hepatic encephalopathy is independently associated with serum hyponatremia [3]. In cirrhosis, ammonia and other neurotoxins induce a low grade cerebral edema, possibly by inducing the synthesis of the osmotically active glutamine in the astrocytes. Moreover, with decreased levels of serum sodium, the osmolality of the extracellular fluid falls. $[4,5]$. This results in a chronic loss of the organic osmolytes, which may predispose the brain to demyelinative lesions upon correction of the hyponatremia $[6,7]$.

Whereas excessively slow correction of hyponatremia is associated with increased morbidity and mortality, inordinately rapid treatment may cause CPM. CPM or osmotic demyelination syndrome is a disorder of pontine white matter as well as other areas of cerebral white matter that was first described in alcoholics. It produces insidious flaccid quadriplegia, mental status change and cranial nerve abnormalities with the pseudobulbar palsy appearance. CPM has been reported in up to $10 \%$ of patients after liver transplantation $[8,9]$. The rate of correction of hyponatremia appears to be of importance in these patients, and a slow correction does not result in CPM [10]. Nevertheless, the magnitude of the change in sodium levels may be of greater significance, as evidenced by data from other studies in which the rate of correction correlated poorly with the development of CPM [11]. Features that are common in patients who develop CPM include delay in the diagnosis of hyponatremia, rapid correction $(>135 \mathrm{mEq} / \mathrm{L})$ within 48 hours of the initiation of therapy, increase of serum sodium by greater than $25 \mathrm{mEq} / \mathrm{L}$ within $48 \mathrm{~h}$, and overcorrection of serum sodium in patients with hepatic encephalopathy [10]. Patients with acute symptomatic hyponatremia and convulsions, stupor or coma should, nevertheless, be treated promptly, since the presence of these CNS symptoms is 
associated with brain edema and may herald impending herniation and cardiorespiratory arrest.

Although preoperative correction of hyponatremia has not been shown to improve outcome [12], it can not be concluded that the intraoperative sodium correction (e.g. through administration of furosemide) is a better therapeutic approach. It is, nevertheless, reasonable to extend the preoperative management of hyponatremia into the intraoperative and postoperative phases of the surgery, with the goal of consistent yet gradual normalization of the serum sodium levels. Frequent control of levels and assessment of neurological examination are of particular importance, and therapy should be modulated accordingly. Despite the association between hyponatremia and poor outcome after transplantation, treatments directed at normalization of serum sodium alone may be unlikely to reduce the perioperative morbidity and mortality, unless other associated problems such as hemodynamic instability, coagulation disturbances and functional status are also corrected. Dr. D'Oyley observation based on these two patients is interesting but we caution against generalizing the suggested approach to all transplant patients. Additional data or a randomized study is warranted.

\section{REFERENCES}

[1] Schrier RW, Lehman D, Zacherle B, Earley LE. Effect of furosemide on free water excretion in edematous patients with hyponatremia. Kidney Int 1973; 3(1): 30-4.

[2] Mackelaite L, Alsauskas ZC, Ranganna K. Renal failure in patients with cirrhosis. Med Clin North Am 2009; 93(4): 855-69.
[3] Guevara M, Baccaro ME, Torre A, et al. Hyponatremia is a risk factor of hepatic encephalopathy in patients with cirrhosis: a prospective study with time-dependent analysis. Am J Gastroenterol 2009; 104(6): 1382-9.

[4] Haussinger D. Low grade cerebral edema and the pathogenesis of hepatic encephalopathy in cirrhosis. Hepatology 2006; 43(6): 118790 .

[5] Haussinger D, Kircheis G, Fischer R, Schliess F, vom Dahl S. Hepatic encephalopathy in chronic liver disease: a clinical manifestation of astrocyte swelling and low-grade cerebral edema? J Hepatol 2000; 32(6): 1035-8.

[6] Haussinger D, Laubenberger J, vom Dahl S, et al. Proton magnetic resonance spectroscopy studies on human brain myo-inositol in hypo-osmolarity and hepatic encephalopathy. Gastroenterology 1994; 107(5): 1475-80.

[7] Restuccia T, Gomez-Anson B, Guevara M, et al. Effects of dilutional hyponatremia on brain organic osmolytes and water content in patients with cirrhosis. Hepatology 2004; 39(6): 161322.

[8] Boon AP, Carey MP, Adams DH, Buckels J, McMaster P. Central pontine myelinolysis in liver transplantation. J Clin Pathol 1991; 44(11): 909-14.

[9] Estol CJ, Faris AA, Martinez AJ, Ahdab-Barmada M. Central pontine myelinolysis after liver transplantation. Neurology 1989; 39(4): 493-8.

[10] Ayus JC, Krothapalli RK, Arieff AI. Treatment of symptomatic hyponatremia and its relation to brain damage. A prospective study. N Engl J Med 1987; 317(19): 1190-5.

[11] Berl T. Treating hyponatremia: what is all the controversy about? Ann Intern Med 1990; 113(6): 417-9.

[12] Hackworth WA, Heuman DM, Sanyal AJ, et al. Effect of hyponatraemia on outcomes following orthotopic liver transplantation. Liver Int 2009; 29(7): 1071-7.

(c) Nozari and Saidi; Licensee Bentham Open.

This is an open access article licensed under the terms of the Creative Commons Attribution Non-Commercial License (http://creativecommons.org/licenses/by$\mathrm{nc} / 3.0 /$ ) which permits unrestricted, non-commercial use, distribution and reproduction in any medium, provided the work is properly cited. 